\title{
Giant arachnoid granulation mimicking dural sinus thrombosis
}

\author{
Ercan Ayaz, Basak Atalay, Begumhan Baysal, Senem Senturk, Ahmet Aslan \\ Department of Radiology, Istanbul Medeniyet University, Goztepe Training and Research Hospital, Istanbul, Turkey
}

\begin{abstract}
Arachnoid granulations (AG) are composed of dense, collagenous connective tissue that includes clusters of arachnoid cells. They tend to invaginate into the dural sinuses, through which cerebrospinal fluid enters the venous system. AG are most commonly seen at the junction between the middle and lateral thirds of the transverse sinuses near the entry sites of the superficial veins. Presently described is the case of a 21-year-old female who presented at the clinic with recurrent headaches. Magnetic resonance (MR) imaging revealed a $3.5-\mathrm{cm}$ lesion, which extended from confluens sinuum through the superior sagittal sinus. The lesion had created a scallop-shaped area of erosion in the neighboring occipital bone. To exclude sinus thrombosis, MR venography was performed, which displayed a maintained venous flow around the lesion. Headaches were treated symptomatically with medical therapy. Giant AG can be misdiagnosed as dural sinus thrombosis. MR imaging combined with MR venography is the most useful diagnostic tool to differentiate giant AG from dural sinus thrombosis.
\end{abstract}

Keywords: Arachnoid granulation; dural sinus thrombosis; magnetic resonance venography; Pacchionian granulation.

\begin{abstract}
A rachnoid granulations (AG) are tufts of arachnoid villi, often invaginated into the dural sinuses, through which cerebrospinal fluid (CSF) enters the venous system [1]. It is thought that hypertrophy occurs in some of the arachnoid villi in response to increasing CSF volume and pressure, forming macroscopic lobulated AG [2]. There is wide variability in site, number, size, and morphology. They routinely measure a few millimeters in size, but may grow to fill and dilate the dural sinuses. They can expand to the inner table of the skull. They frequently have a close relationship to the bridging veins that penetrate the dural venous sinuses. These structures form weak areas in the dura, through which perivascular arachnoid extrusion can occur [3]. They are often discovered as an
\end{abstract}

incidental finding in the transverse and posterosuperior sagittal sinus, though rarely, they have been reported to cause symptoms from venous hypertension secondary to partial sinus occlusion [1].

This report is a description of the case of a patient with recurrent episodes of moderate headache whose brain magnetic resonance (MR) imaging revealed incidental giant AG involving the confluens sinuum and extending through the superior sagittal sinus.

\section{CASE REPORT}

A 21-year-old female patient presented at the hospital with recurrent headaches. Neurological examination revealed normal findings. Brain MRI was per-

Received: April 24, 2015 Accepted: February 27, 2017 Online: August 26, 2017

Correspondence: Dr. Ercan AYAZ. Dr. Erkin Caddesi, Goztepe Egitim ve Arastirma Hastanesi, Radyoloji Klinigi, Kadikoy, Istanbul, Turkey. 

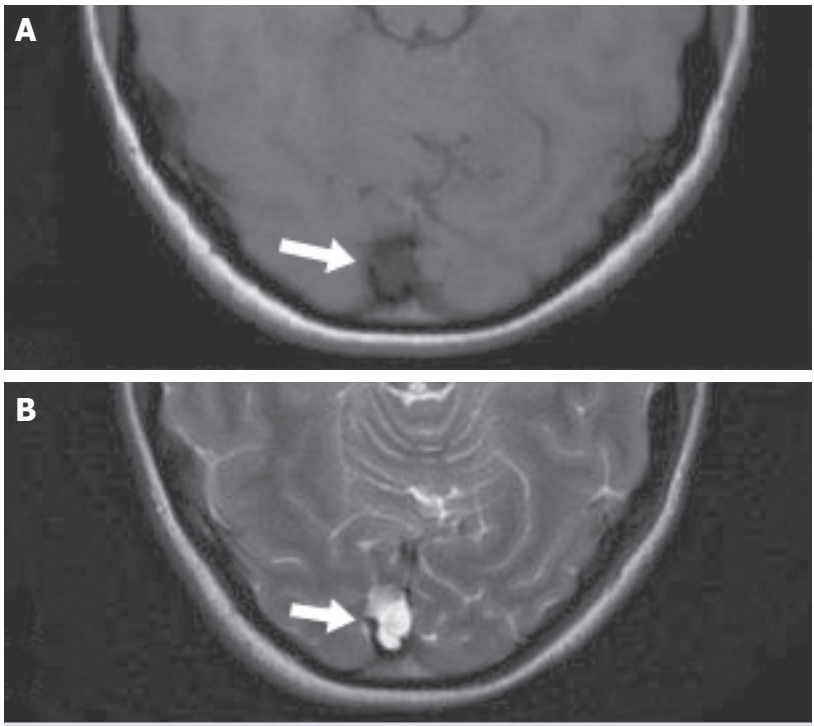

FIGURE 1. (A) Axial T1-weighted image shows hypointense, lobulated contour lesion (arrow) within the confluens sinuum; (B) Axial T2-weighted image demonstrates lesion is hyperintense relative to brain parenchyma.

formed and showed a 3.5-cm lesion, which extended from the confluens sinuum through the superior sagittal sinus. The lesion was hypointense relative to the brain on T1-weighted image (WI), hyperintense relative to the brain on T2-WI (Figure 1), with banded lower signal, most likely representing collagenous connective tissue and complete suppression on fluid-attenuated inversion recovery sequences. The lesion had caused a scallop-shaped area of erosion in the neighboring occipital bone (Figure 2). Due to the bony erosion and singularity, the lesion was identified as AG. To exclude sinus thrombosis, MR venography was recommended. The patient requested a scan without contrast agent; therefore, non-contrast 2-dimensional time-of-flight (TOF) MR venography was performed. It was observed that there was maintained venous flow around the lesion (Figure 3). The left jugular and left transverse veins were hypoplasic. The headaches were treated symptomatically with medical therapy.

\section{DISCUSSION}

AG are composed of dense collagenous connective tissue that includes clusters of arachnoid cells in a delicate network within the vascular space filled with CSF from the contiguous subarachnoid

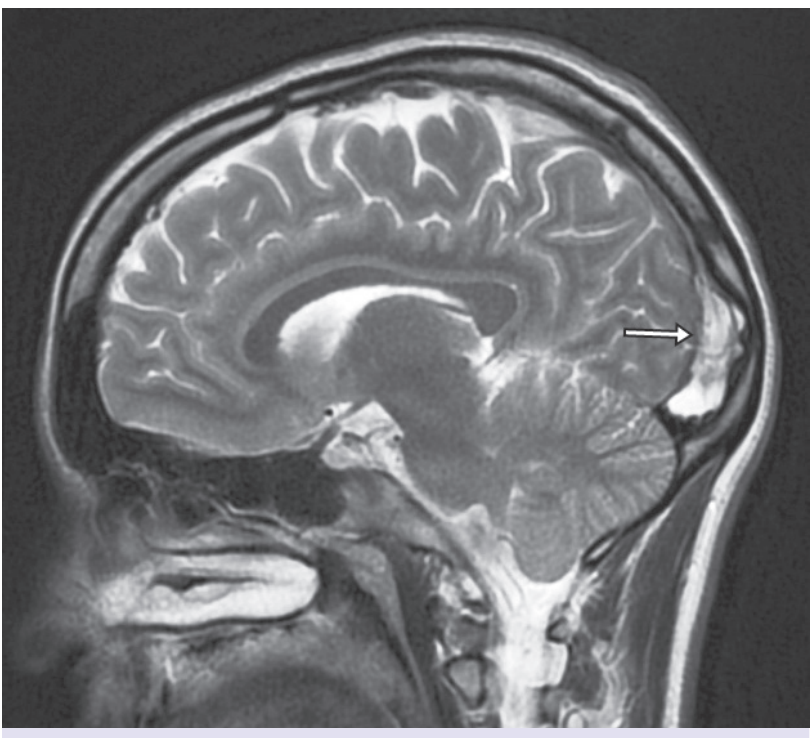

FIGURE 2. Sagittal T2-weighted image indicates hyperintense lesion (arrow) extending from confluens sinuum through the superior sagittal sinus and scallop-shaped area of erosion in the neighboring bone.

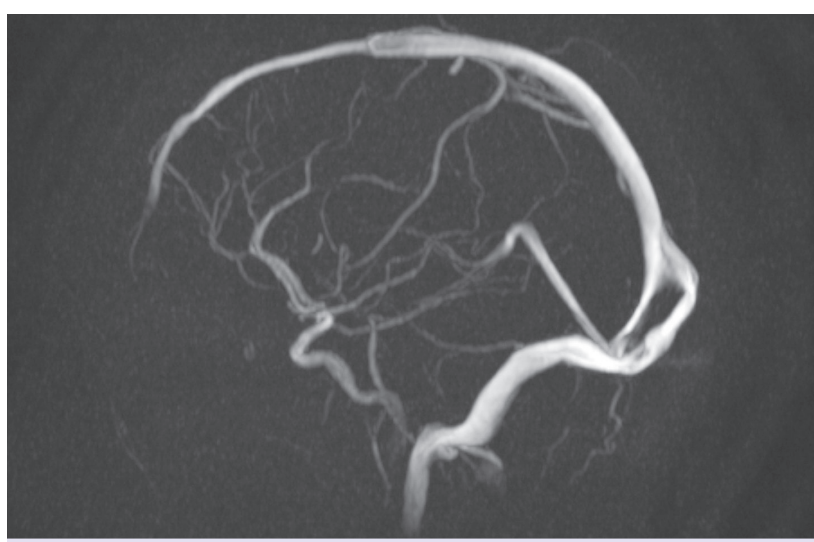

FIGURE 3. Sagittal magnetic resonance venography maximum intensity projection image revealing obvious venous flow, which divided into 2 channels around filling defect (arachnoid granulation), and joined distally.

space. This cell layer is continuous with the underlying arachnoid membrane [4]. Growth of arachnoid membrane-like projections into the dural sinus was first described by Pacchioni in 1705 [5]. These projections are called arachnoid villi or $A G$, depending on size. Arachnoid villi are microscopic, whereas AG are macroscopic structures. CSF is synthesized and produced by the choroid plexus, where it circulates to the subarachnoid space and eventually returns to the venous blood via AG. AG 
have wide variability in location, number, size, and morphology. Occasionally, AG can extend partly up to the inner table of the skull as foveolae granulations, and even expand into the diploic space, and eventually involve the outer table, mimicking malignant osteolytic lesion [6]. It has been proposed that some AG increase in number and size with age in response to increasing CSF volume and pressure [1]. AG are most commonly seen at the junction between the middle and lateral thirds of the transverse sinuses (92\%) near the entry sites of the superficial veins [7].

The clinical significance of $A G$ is uncertain. Although giant AG are often discovered as an incidental finding in the transverse and posterior superior sagittal sinus, rarely, they cause symptoms of increased intracranial pressure as result of venous hypertension secondary to partial sinus occlusion.

Typically, regardless of size, AG were diagnosed by identifying intra-AG fluid revealed as CSF-like attenuation on computed tomography (CT) and parallel CSF signal intensity on all MRI sequences, which was the conventional diagnostic criterion for AG. It was thought that identification of AG could be facilitated by a characteristic appearance: round or oval shape, well-defined outline, and homogenous intensity. Presence of an adjacent cortical vein can be considered an additional supportive element [7].

In the differential diagnosis of a mass within the dural sinus, many diseases, including meningioma, inclusion tumor, sinus cavernoma, and meningocele, can be excluded by characteristic imaging findings. It is particularly important to differentiate AG from dural sinus thrombosis, which may cause a fatal outcome and requires an immediate approach. Thrombosis usually involves an entire segment of a sinus or multiple sinuses, and can extend to the cortical veins, whereas $A G$ produce focal, well-defined, nodular defects in the sinuses. Typical MRI finding of dural sinus thrombosis is a clot in the sinus that is iso- to hyperintense on T1-WI and hyperintense on T2-WI. A key MRI feature of giant AG is a nonenhancing lesion with central linear enhancement and surrounding blood flow on contrast enhanced MR venography. Thrombus within the sinus may show contrast enhancement and venous flow occlusion. Focal central linear enhancement in the arachnoid nodule may represent extension of the endothelium-lined venous sinuses into the fissure of the granulation [6]. The conventional TOF MR venography technique, which does not require the use of a paramagnetic contrast agent, has evolved as a reliable and clinically accepted method for assessment of the venous system [8]. However, this technique has limitations: it is susceptible to pulsatility, in-plane saturation effects, and spin dephasing when laminar flow is disturbed [8].

In conclusion, it should be kept in mind that giant AG may be misdiagnosed as dural sinus thrombosis, which requires immediate approach. Before diagnosing focal, nodular defect in the sinuses as thrombosis, giant AG should be considered as a differential diagnosis. MRI and contrast-enhanced MRI venography are the most useful diagnostic tools to differentiate giant AG from dural sinus thrombosis.

\section{Conflict of Interest: None declared.}

Financial Disclosure: The authors declared that this study has received no financial support.

Authorship contributions: Concept - B.B.; Design - B.A.; Supervision - S.S.; Materials - B.A., E.A.; Data Collection E.A.; Analysis - B.A., B.B.; Literature Search - E.A.; Writing - E.A.; Critical Review - S.S, A.A.

\section{REFERENCES}

1. Kan P, Stevens EA, Couldwell WT. Incidental giant arachnoid granulation. AJNR Am J Neuroradiol 2006;27:1491-2.

2. Lu CX, Du Y, Xu XX, Li Y, Yang HF, Deng SQ, et al. Multiple occipital defects caused by arachnoid granulations: Emphasis on T2 mapping. World J Radiol 2012;4:341-4.

3. Haybaeck J, Silye R, Soffer D. Dural arachnoid granulations and "giant" arachnoid granulations. Surg Radiol Anat 2008;30:417-21.

4. Brunori A, Vagnozzi R, Giuffrè R. Antonio Pacchioni (1665-1726): early studies of the dura mater. J Neurosurg 1993;78:515-8.

5. Choi HJ, Cho CW, Kim YS, Cha JH. Giant arachnoid granulation misdiagnosed as transverse sinus thrombosis. J Korean Neurosurg Soc 2008;43:48-50.

6. Leach JL, Jones BV, Tomsick TA, Stewart CA, Balko MG. Normal appearance of arachnoid granulations on contrast-enhanced $\mathrm{CT}$ and MR of the brain: differentiation from dural sinus disease. AJNR Am J Neuroradiol 1996;17:1523-32.

7. Haroun AA, Mahafza WS, Al Najar MS. Arachnoid granulations in the cerebral dural sinuses as demonstrated by contrastenhanced 3D magnetic resonance venography. Surg Radiol Anat 2007;29:323-8.

8. Ayanzen RH, Bird CR, Keller PJ, McCully FJ, Theobald MR, Heiserman JE. Cerebral MR venography: normal anatomy and potential diagnostic pitfalls. AJNR Am J Neuroradiol 2000;21:74-8. 